\title{
High glucose induces epithelial-mesenchymal transition and results in the migration and invasion of colorectal cancer cells
}

\author{
JIAYAN WU ${ }^{1}$, JIAYI CHEN $^{1}$, YANG XI $^{1}$, FUYAN WANG $^{1}$, HONGCUN SHA $^{2}$, LIN LUO $^{3}$, \\ YABIN ZHU ${ }^{3}$, XIAOMING HONG ${ }^{2}$ and SHIZHONG BU ${ }^{1,3}$ \\ ${ }^{1}$ Runliang Diabetes Laboratory, Diabetes Research Center, School of Medicine, Ningbo University, Ningbo, Zhejiang 315211; \\ ${ }^{2}$ Department of General Surgery, Ningbo Urology and Nephrology Hospital, School of Medicine, Ningbo University, \\ Ningbo, Zhejiang 315192; ${ }^{3}$ School of Medicine, Ningbo University, Ningbo, Zhejiang 315211, P.R. China
}

Received October 17, 2017; Accepted March 9, 2018

DOI: $10.3892 / \mathrm{etm} .2018 .6189$

\begin{abstract}
Diabetes mellitus (DM) is associated with an increased risk of colorectal cancer (CRC). Hyperglycemia, a chronic abnormality in diabetes, is an independent predictor of cancer-associated mortality in CRC. However, the underlying biological mechanism of hyperglycemia in CRC cells is largely unknown. In the present study, HCT-116 and HT-29 cell proliferation, apoptosis, migration and invasion were assessed. In addition, the expression of epithelial (E)-cadherin, vimentin and high-mobility group A protein 2 (HMGA2) were assessed using western blotting. The results demonstrated that high glucose ( $\mathrm{HG} ; 30 \mathrm{mmol} / \mathrm{l})$ caused CRC cells to lose their epithelial morphology, with a decrease in E-cadherin and an increase in vimentin, suggesting epithelial-mesenchymal transition (EMT). Furthermore, HG significantly enhanced the cell migration and invasion of CRC cells and the expression of HMGA2. Transfection with HMGA2 small interfering RNA reversed the $\mathrm{HG}$-induced changes to $\mathrm{CRC}$ cells. In addition, HG promoted CRC cell proliferation and suppressed apoptosis. The results of the present study suggest that hyperglycemia promotes EMT, proliferation, migration and invasion in CRC cells and may provide novel insights into the link between $\mathrm{HG}$ and CRC.
\end{abstract}

Correspondence to: $\mathrm{Dr}$ Shizhong Bu, Runliang Diabetes Laboratory, Diabetes Research Center, School of Medicine, Ningbo University, 818 Fenghua Road, Ningbo, Zhejiang 315211, P.R. China E-mail: shizhongbu@nbu.edu.cn

Dr Xiaoming Hong, Department of General Surgery, Ningbo Urology and Nephrology Hospital, School of Medicine, Ningbo University, 1 Qianhe Road, Ningbo, Zhejiang 315192, P.R. China E-mail: hongxiaoming2002@aliyun.com

Abbreviations: DM, diabetes mellitus; CRC, colorectal cancer; EMT, epithelial-mesenchymal transition; HMGA2, high-mobility group A protein 2; DMEM, Dulbecco's modified Eagle's medium

Key words: colorectal cancer, epithelial-mesenchymal transition, high glucose

\section{Introduction}

Colorectal cancer (CRC) is one of the most common malignant tumors and the leading cause of cancer-associated mortality in humans (1). CRC is the third most commonly diagnosed cancer in males and the second in females, with an estimated 1.4 million cases and 693,900 deaths occurring worldwide in 2012 (2). In the USA, CRC is the third leading cause of cancer-associated mortality (3), while tumor invasion and metastasis are the leading causes of patient mortality (4). Many CRCs are metastatic at the time of diagnosis (5). Diabetes mellitus (DM) is a metabolic disorder characterized by increased blood glucose levels (6) and is considered to be one of the most important health problems worldwide (7). It has been demonstrated that DM is associated with an elevated risk of CRC in both men and women (8). A meta-analysis of 8 studies identified a positive correlation between type 2 (T2)DM with a 1.21-fold increased risk of CRC (9). Patients with colorectal cancer and DM have an increased risk of cancer-specific mortality and have worse disease-free survival than those who do not have DM $(10,11)$. DM has also been reported to be a risk factor for CRC, although this remains controversial (11-14).

Epithelial-mesenchymal transition (EMT) is the morphological transformation of epithelial-like cancer cells to an elongated mesenchymal phenotype (15). During EMT, cancer cells stop expressing adhesion proteins, including epithelial (E)-cadherin and claudin-1, and increase the expression of mesenchymal phenotype markers, including vimentin, neural (N)-cadherin and Snail (16). EMT serves an important role in the invasion and metastasis of CRC (17) and is able to induce circulating tumor cell properties in transformed colorectal epithelial cells (18). Furthermore, EMT is highly prognostic for colon cancer recurrence (19). High glucose (HG) induces EMT in breast cancer cells (20) and human peritoneal mesothelial cells (21); however, this effect has not been studied in CRC.

The aim of the present study was to investigate the association between $\mathrm{HG}$ and the migration, invasion and apoptosis of colorectal cancer cells. The expression of EMT-associated proteins was detected and the underlying mechanisms were investigated. 


\section{Materials and methods}

Cell culture and transfection. The human CRC cell lines HCT-116 and HT-29 were obtained from American Type Culture Collection (Manassas, VA, USA). Both cell lines were cultured in Dulbecco's modified Eagle's medium (DMEM; Genom Biotech Pvt., Ltd., Bhandup, Mumbai) containing 10\% fetal bovine serum (FBS; Atlanta Biologicals, Flowery Branch, GA, USA), 100 unit/ml penicillin, $100 \mu \mathrm{g} / \mathrm{ml}$ streptomycin with normal glucose (NG; $5.5 \mathrm{mmol} / \mathrm{l})$ or $\mathrm{HG}(30 \mathrm{mmol} / \mathrm{l})$. Cultures were maintained at $37^{\circ} \mathrm{C}$ in a humidified atmosphere containing $5 \% \mathrm{CO}_{2}$.

Human samples. A total of 6 CRCs with or without T2DM in this study were histologically and clinically diagnosed at Ningbo Urology and Nephrology Hospital between October 2015 to March 2016 and the tissues were collected immediately following surgical resection for diagnosis. The inclusion criteria was as follows: i) Patients had to be diagnosed with $\mathrm{CRC}$ by preoperative pathological biopsy using a colonoscope; ii) aged between 18 and 75 years; iii) exhibit no distant metastasis; and iv) with or without diabetes. Patients were excluded if they: i) Received radiotherapy and chemotherapy prior to surgery; ii) exhibited acute infection; or iii) had a history of abdominal surgery or other malignant tumors. The specimens were then stored at $-80^{\circ} \mathrm{C}$. The present study was approved by Ningbo Yinzhou Ethics Committee and signed informed consent was obtained from the patients or their family. Patient data is summarized in Table I.

Immunofluorescence. CRC tissues were fixed in $4 \%$ formaldehyde solution for $2 \mathrm{~h}$ at $25^{\circ} \mathrm{C}$ and then sectioned into $5-\mu \mathrm{M}$-thick frozen sections. The sections were washed in cold PBS 3 times and subsequently blocked with $2 \%$ bovine serum albumin $\mathrm{V}$ at $25^{\circ} \mathrm{C}$ (BSA-V; Beijing Solarbio Science \& Technology Co., Ltd., Beijing, China) for $1 \mathrm{~h}$. Samples were incubated with primary antibodies against E-cadherin (1:20; sc-8426; Santa Cruz Biotechnology, Inc., Dallas, TX, USA) diluted with 1\% BSA-V overnight at $4^{\circ} \mathrm{C}$. Following 3 washes with PBS, the sections were incubated with tetramethylrhodamine conjugated goat anti-rabbit secondary antibody (1:1,000; sc-362281; Santa Cruz Biotechnology, Inc.) diluted with $1 \%$ BSA-V in the dark for $1 \mathrm{~h}$ at $25^{\circ} \mathrm{C}$ and washed in PBS again for 3 times. DAPI diluted with PBS was used to stain the nuclei at $25^{\circ} \mathrm{C}$. Images at a magnification of $\mathrm{x} 40$ were captured using an inverted fluorescence microscope (Nikon Corp., Tokyo, Japan).

Western blotting. Tissues and cells were homogenized in a radioimmunoprecipitation assay lysis buffer (Beijing Solarbio Science \& Technology Co., Ltd.). A BCA protein assay kit (Cwbiotech, Beijing, China) was used to determine protein concentrations. Proteins $(20 \mu \mathrm{g})$ were separated by $10 \%$ SDS-PAGE and electrotransferred to polyvinylidene fluoride membranes, which were blocked in 5\% nonfat milk for $1 \mathrm{~h}$ at $25^{\circ} \mathrm{C}$ and probed with primary antibodies against E-cadherin (1:400; \#AF0131; Affinity Biosciences, Jiangsu, China), vimentin (1:600; \#AF0292; Affinity Biosciences), GAPDH (1:10,000; \#T0004; Affinity Biosciences) and high-mobility group A protein 2 (HMGA2; 1:500; 5269s; Cell Signaling Technology, Inc., Danvers, MA, USA) overnight at $4^{\circ} \mathrm{C}$. The membranes were subsequently incubated with goat anti-rabbit antibody diluted with 0.3\% TBST (1:1,000; \#SC2004; Santa Cruz Biotechnology, Inc.) or goat anti-mouse antibody diluted with 0.3\% TBST (1:1,000; \#SC2005; Santa Cruz Biotechnology, Inc.) for $1 \mathrm{~h}$ at room temperature. The membranes were scanned with the Tanon 5200 automated image analysis system (Tanon, Shanghai, China) and the ImageJ software (version 1.48U; National Institutes of Health, Bethesda, MD, USA) was used to evaluate the band intensity.

Scratch assay. HCT-116 and HT-29 cells (3-5x10 5 cells/well) were seeded in 6-well plates and cultured in DMEM containing $\mathrm{NG}$ or $\mathrm{HG}$ for 4 days at $37^{\circ} \mathrm{C}$. Confluent cultures were scratched with sterile $200 \mu \mathrm{l}$ pipette tips and washed gently with PBS to remove floating cells. Then the cells were cultured in DMEM containing $\mathrm{NG}$ or $\mathrm{HG}$ and 5\% FBS. Cells were viewed under an inverted fluorescence microscope (magnification, $\mathrm{x} 40$ ) and images were captured after 0, 24, 48 and $72 \mathrm{~h}$.

Transwell assays. HCT-116 and HT-29 cells were cultured in DMEM containing NG or $\mathrm{HG}$ for 4 days and then serum-starved for $12 \mathrm{~h}$. The cells $\left(1 \times 10^{5}\right.$ cells/well $)$ were seeded into Boyden chambers (EMD Millipore, Billerica, MA, USA) with $8-\mu \mathrm{m}$ pore size filter membranes. The inserts were coated with Matrigel (BD Biosciences, Franklin Lakes, NJ, USA) for invasion assays or not coated for migration assays. The chambers were then placed in 24-well plates containing DMEM and $10 \% \mathrm{FBS}$ at $37^{\circ} \mathrm{C}$. After $72 \mathrm{~h}$, the non-invaded cells on the upper side of the filter were removed with a cotton swab and cells attached to the underside of the membrane were fixed in ethanol, stained with crystal violet and images were counted using a microscope (CKX41; Olympus Corporation, Tokyo, Japan; magnification, $\mathrm{x} 40$ ).

HMGA2 knockdown. The RNA interference technique was used to downregulate HMGA2 in HCT-116 and HT-29 cells (22). HMGA2 small interfering $400 \mathrm{ng}$ (si)RNAs (siHMGA2-1, 5'-GAA AGCAGAGACCAUUGGATT-3'; siHMGA 2-2, 5'-GAA AGCAGAGACCAUUGG ATT-3'; Shanghai Genechem Co., Ltd., Shanghai, China) were synthesized and transfected into cells using RNAiMAX (Invitrogen; Thermo Fisher Scientific, Inc., Waltham, MA, USA) according to the manufacturer's protocol. Following $48 \mathrm{~h}$ transfection, HMGA2 expression was confirmed by western blotting. Western blotting was then performed as aforementioned.

MTT assay. HCT-116 and HT-29 proliferation was measured using an MTT assay. Cells were incubated with $0.35 \mathrm{mg} / \mathrm{ml}$ MTT solution at $37^{\circ} \mathrm{C}$ for $4 \mathrm{~h}$. The medium was removed, $100 \mu 1$ dimethylsulfoxide (DMSO) was added and the mixture was vortexed at $112 \mathrm{x} \mathrm{g}$ for $10 \mathrm{~min}$ at $25^{\circ} \mathrm{C}$. The optical density was read at $490 \mathrm{~nm}$ and all experiments were performed 3 times.

Ki-67 expression and apoptosis analysis. Cells were seeded in 6-well plates and treated with $\mathrm{NG}$ or HG, respectively, for 4 days. Cells were digested using $1 \mathrm{ml}$ trypsin (\#C0201; Beyotime Institute of Biotechnology, Beijing, China), washed twice with PBS and incubated in $100 \mu \mathrm{l}$ fixation buffer (Biolegend, Inc., San Diego, CA, USA) at room temperature 
Table I. Patient data.

\begin{tabular}{lcccc}
\hline Patients & Number of patients & Age & Sex ratio (F:M) & Comorbidities \\
\hline With diabetes & 3 & $56-64$ & $2: 1$ & No comorbidities \\
Without diabetes & 3 & $60-65$ & $2: 1$ & One with hypertension
\end{tabular}

for $15 \mathrm{~min}$. Cells were then washed with $100 \mu \mathrm{l}$ permeabilisation buffer (Biolegend, Inc.). Following centrifugation at $1,500 \mathrm{x} \mathrm{g}$ for $3 \mathrm{~min}$ at $25^{\circ} \mathrm{C}$, the cells were resuspended in $100 \mu \mathrm{l}$ permeabilisation wash buffer containing Alexa Fluor 647 mouse anti-Ki-67 antibody (1:100; 561126; BD Biosciences) and incubated at room temperature in the dark for $30 \mathrm{~min}$. A total of $400 \mu \mathrm{l}$ permeabilisation wash buffer was added to resuspend the cells for flow cytometric analysis using a FACS flow cytometer (BD Biosciences).

Cell apoptosis was assayed using the Annexin Vphycoerythrin (PE) Apoptosis Detection kit (BD Biosciences). Cells were washed twice with cold PBS and resuspended in Annexin $\mathrm{V}$ Binding buffer at a concentration of $1.0 \times 10^{6}$ cells $/ \mathrm{ml}$. Specifically, this suspension $(100 \mu \mathrm{l})$ comprised $1 \mu \mathrm{l}$ Annexin V-PE, $1 \mu 1$ 7-aminoactinomycin D and $98 \mu \mathrm{l}$ Binding buffer. The cells were vortexed gently and incubated for $15 \mathrm{~min}$ at room temperature in the dark. To each tube, $400 \mu \mathrm{l}$ of Binding buffer added and cells were analyzed using a FACS flow cytometer (BD Biosciences) and FlowJo 7.6 software (FlowJo LLC, Ashland, OR, USA).

Statistical analysis. Data are expressed as the mean \pm standard deviation. One-way analysis of variance was used to test the Homogeneity of variance, then a Mann-Whitney U was used to compare differences between groups. All statistical analyses were performed using GraphPad Prism 6.0 (GraphPad Software, Inc., La Jolla, CA, USA) and SPSS 18.0 software (SPSS, Inc., Chicago, IL, USA). P<0.05 was considered to indicate a statistically significant difference.

\section{Results}

HG induces EMT in CRC tissues and cells. E-cadherin protein expression was measured in tumor tissues from 3 patients with CRC and DM and 3 patients with CRC without DM using immunofluorescence and western blotting. The area of tumor cells with positive E-cadherin staining was increased in patients without DM compared with those with DM (Fig. 1A). Furthermore, the results of western blotting confirmed that the expression of E-cadherin protein was lower in patients with DM compared with patients without DM (Fig. 1B); however, the expression of vimentin protein was significantly higher in patients with DM compared with those without DM (Fig. 1B). HCT-116 and HT-29 cells were exposed to HG for 4 days and it was demonstrated that $\mathrm{HG}$ reduced the expression of E-cadherin protein, whereas the expression of vimentin protein was increased (Fig. 1C). These results suggest that $\mathrm{HG}$ serves an important role in the EMT of CRC cells.

$H G$ promotes the migration and invasion of CRC cells. EMT is characterized by a loss of cell-to-cell adhesion and increased cell migration and invasion (23). As such, the effect of HG on the metastatic capability of CRC cells was investigated. Scratch assays revealed that wound healing was faster in HCT-116 and HT-29 cells grown in HG conditions compared with those grown in NG (Fig. 2A and B). Furthermore, HG accelerated the cells ability to invade and migrate compared with NG (Fig. 2C and D). These results suggest that $\mathrm{HG}$ is able to promote the invasion and migration of CRC cells.

$H G$ promotes EMT by increasing the level of HMGA2 protein. HMGA2 is known to control the expression of a diverse set of transcription factors associated with the regulation of E-cadherin transcription $(24,25)$. HMGA2 has been reported to regulate EMT in gastric cancer $(26,27)$, tongue squamous cell carcinoma (28) and prostate cancer cells (29). As such, it was hypothesized that HMGA2 may regulate $\mathrm{HG}$-induced EMT and the expression of HMGA2 in CRC cells exposed to $\mathrm{HG}$ or NG for 4 days was assessed. HMGA2 was significantly upregulated in HG-stimulated cells compared with those treated with NG (Fig. 3A and B). HMGA2 expression was knocked down in HCT-116 and HT-29 cells and confirmed used western blotting (Fig. 3C and D). The results revealed that HMGA2 knockdown significantly increased E-cadherin protein expression and decreased vimentin protein expression in HG-stimulated cell compared with those treated with NG (Fig. 3E and F).

$H G$ enhances cell viability and suppresses apoptosis in CRC cells. To characterize the functional roles of HG in cell proliferation, MTT assays were performed and Ki-67 was measured. The results revealed that $\mathrm{HG}$ enhances the viability of HCT-116 and HT-29 cells in a time-dependent manner (Fig. 4A and B). $\mathrm{Ki}-67$ is a nuclear antigen present only in proliferating cells and is one of the most widely used proliferation-associated markers in cancer cells (30). Ki-67 staining demonstrated that HG enhances the expression of $\mathrm{Ki}-67$ and therefore the proliferation of HCT-116 and HT-29 cells compared with NG (Fig. 4C and D). The role of HG on apoptosis in HCT-116 and HT-29 cells was also assessed and it was revealed that HG significantly decreased apoptosis compared with HG (Fig. 4E and F).

\section{Discussion}

Impaired metabolism and unlimited growth are two hallmarks of cancer and serve an important role in cancer progression (31) and DM promotes the growth and metastasis of tumor cells (32). The results of the present study demonstrate that $\mathrm{HG}$ increases HMGA2 expression and induces EMT in CRC cells.

The invasive and migratory capabilities of CRC cells were significantly enhanced by $\mathrm{HG}$, while transfection with 
A CRC patients
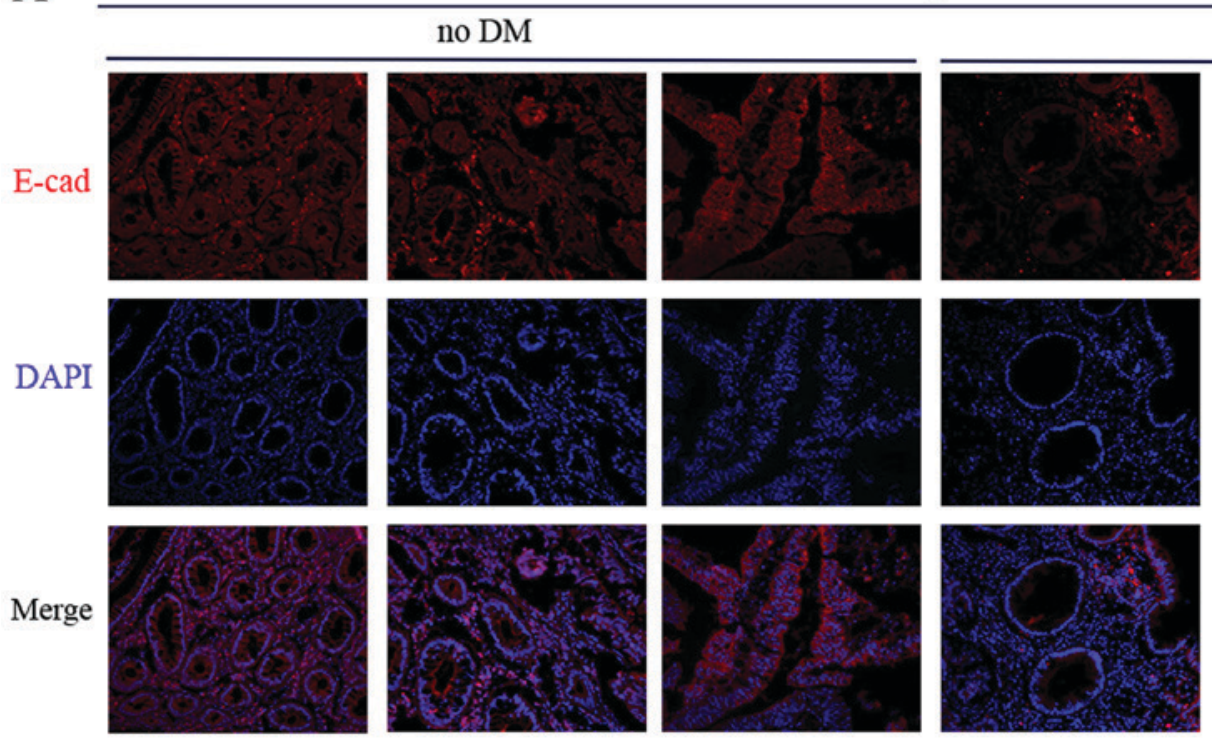

with DM
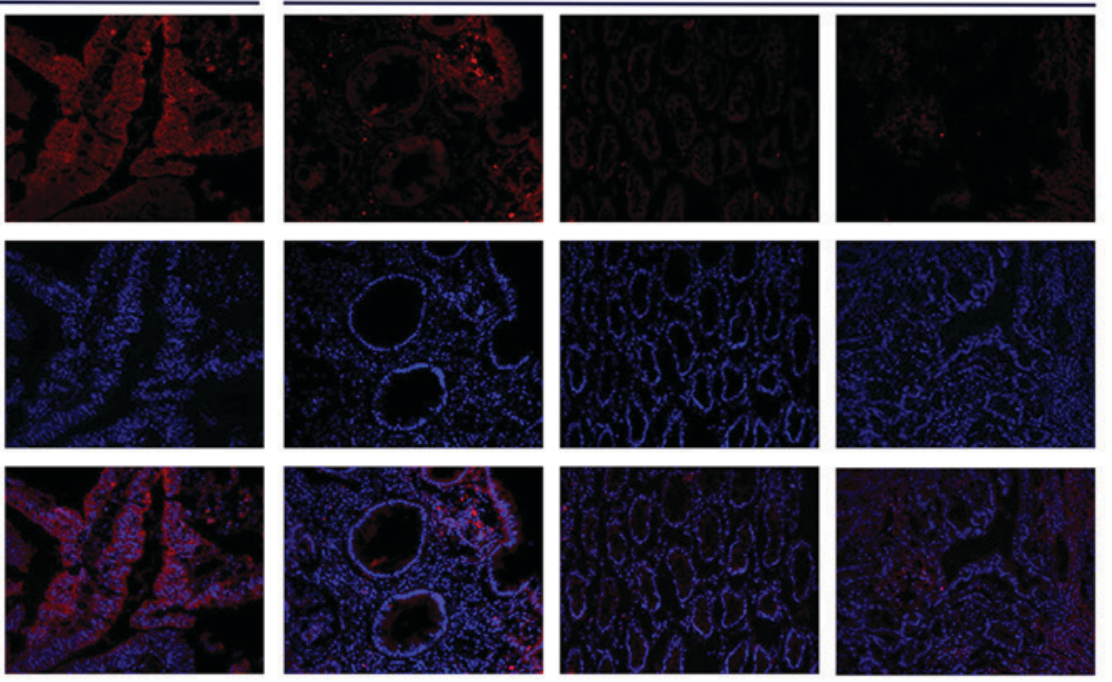

B

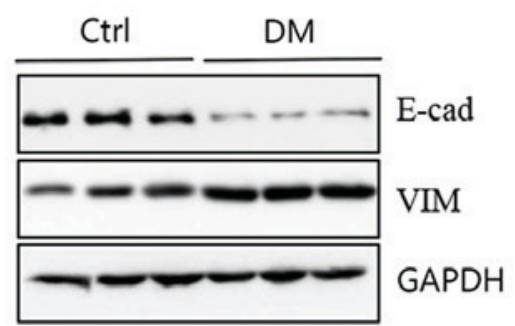

C
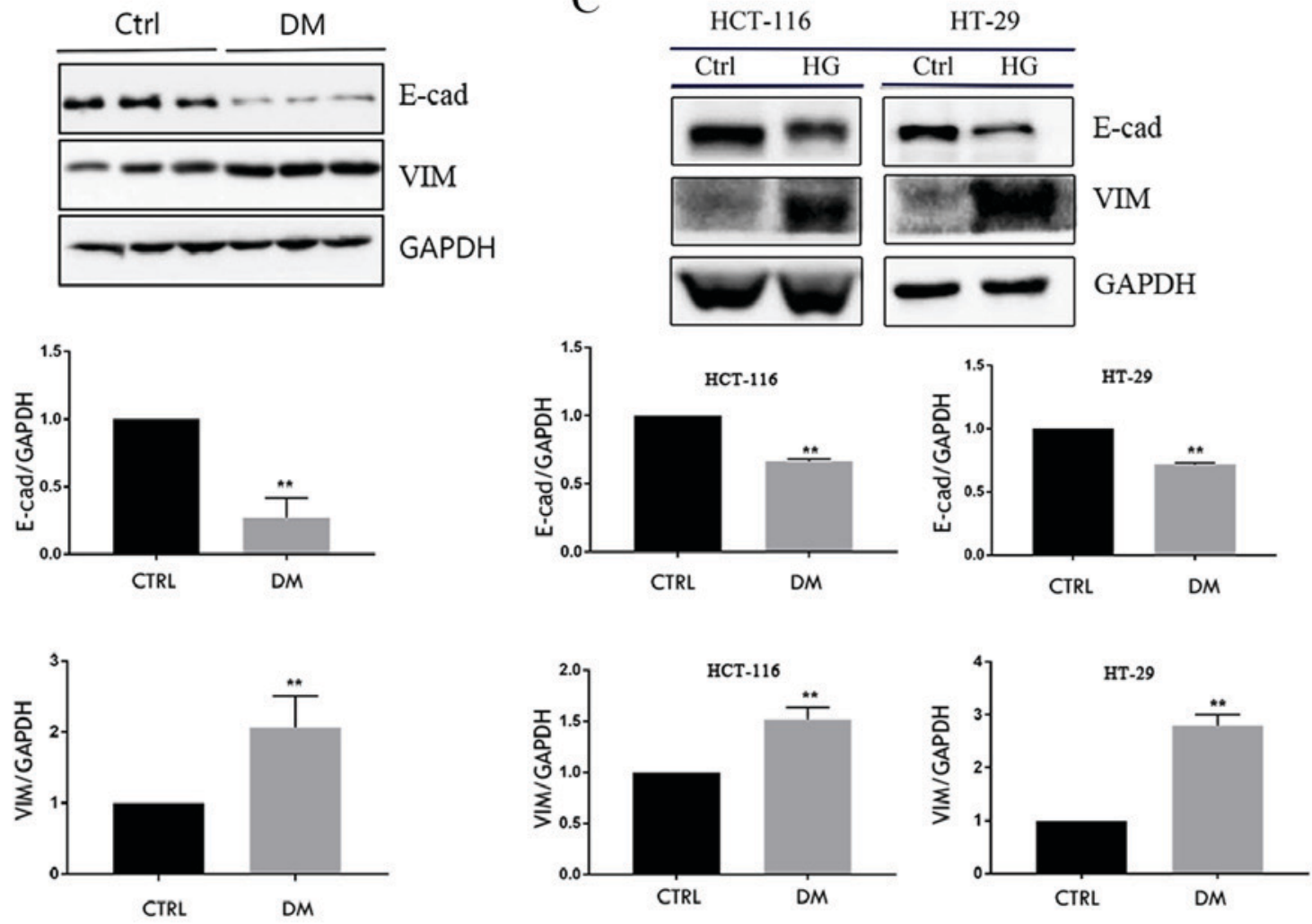

Figure 1. HG promotes epithelial-mesenchymal transition in patients with CRC and CRC cells. (A) Immunofluorescence for E-cad in tumors from patients with CRC with or without DM (magnification, $\mathrm{x} 40$ ). Western blot analyses of E-cad and VIM in (B) CRC tissues and (C) HCT-116 and HT-29 cells. ** P $<0.01$ vs. Ctrl. HG, high glucose (30 mmol/l); CRC, colorectal cancer; E-cad, epithelial cadherin; DM, diabetes mellitus; VIM, vimentin; Ctrl, control.

HMGA2 siRNA suppressed HG-induced EMT in HCT-116 and HT-29 cells. In addition, HG enhanced the proliferation and reduced the apoptosis of CRC cells. These results suggest that DM causes EMT and promotes metastasis in CRC cells. As such, DM may induce CRC tumor growth.

DM has been reported to have pro-migratory and proinvasive effects in both normal (33) and cancer cells (34-38). Epidemiological studies have previously established an association between inflammation and DM (39-41). The chronic inflammatory response may contribute to DM development by causing insulin resistance, which in turn intensifies hyperglycemia to promote long-term complications of diabetes (42). Furthermore, inflammation induces EMT in CRC $(43,44)$. Previous research has verified that $\mathrm{HG}$ induces EMT in pancreatic and breast cancers (45). Similarly, the results of the present study demonstrate that DM is associated with the downregulation of E-cadherin and upregulation of vimentin in patients with CRC. Meanwhile, HG induces EMT in CRC 
A
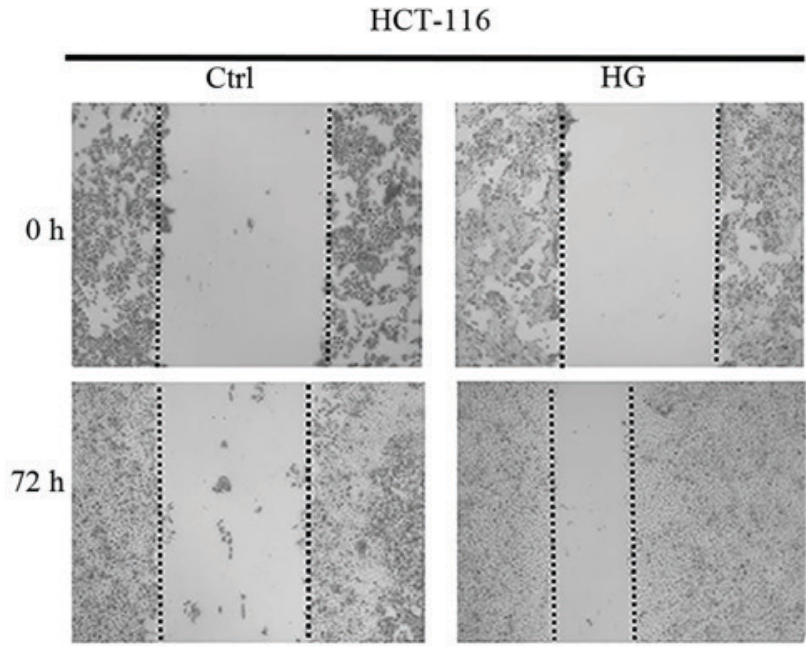

C

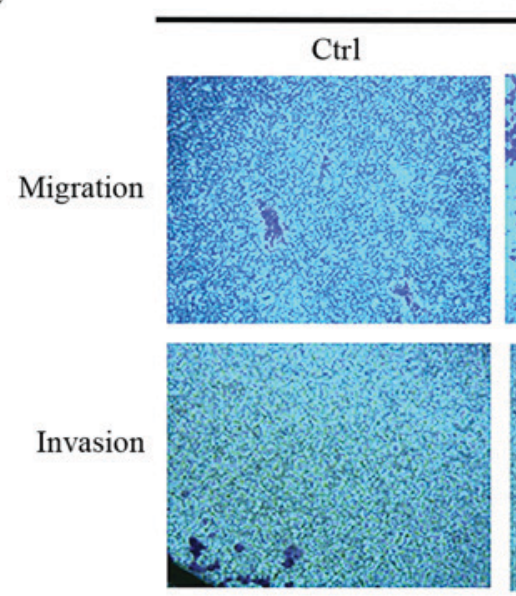

HCT-116
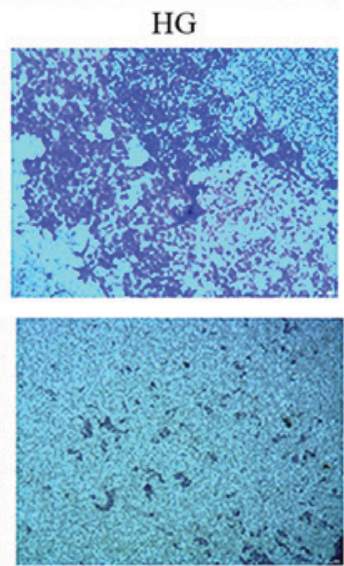

B

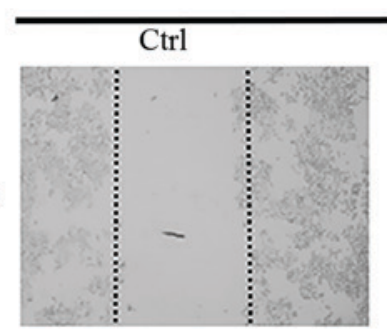

HT-29

$72 \mathrm{~h}$
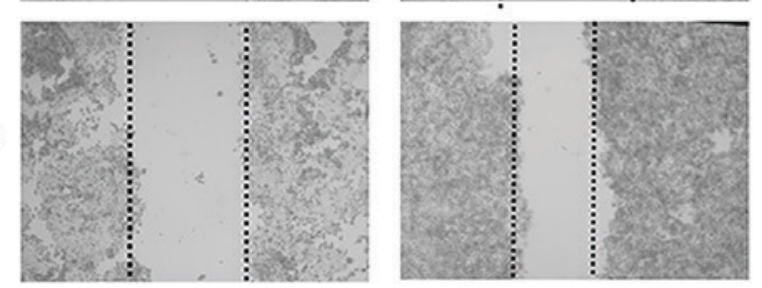

D
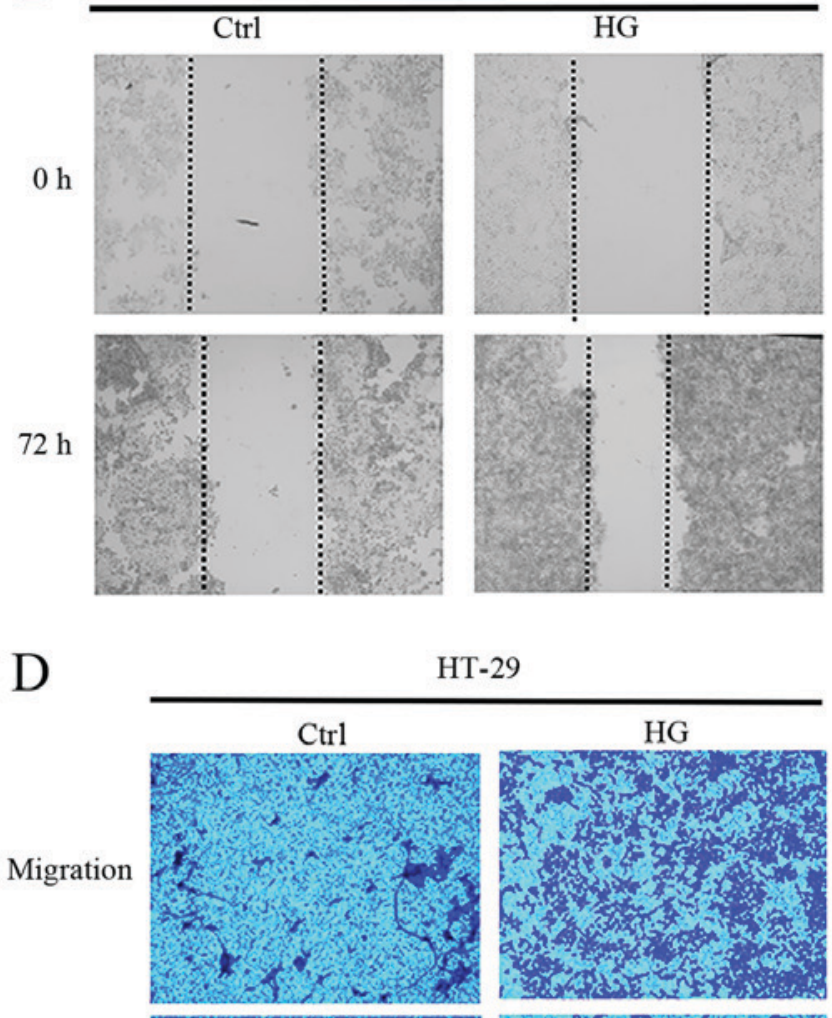

HT-29

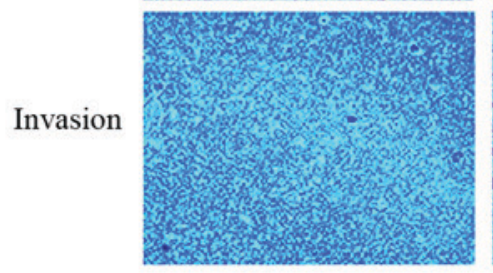

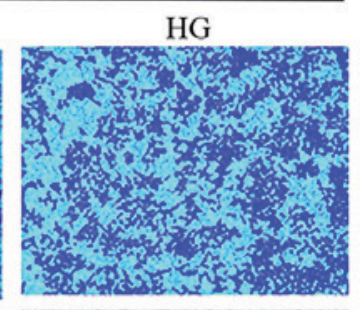

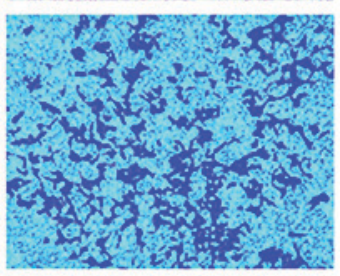

Figure 2. HG promotes the migration and invasion of HCT-116 and HT-29 cells. The migratory abilities of (A) HCT-116 and (B) HT-29 cells were determined using a scratch assay following HG stimulation (magnification, x40). A Transwell assay was also performed to assess the migration and invasion abilities of (C) HCT-116 and (D) HT-29 cells (magnification, x40). HG, high glucose; Ctrl, control.

cells in vitro. Downregulated E-cadherin expression is associated with lymph node metastases, poor tumor differentiation and worse prognosis in patients with CRC $(46,47)$. Conversely, increased vimentin expression is significantly associated with lymph node metastasis and poor prognosis in CRC (48). The results of the present study demonstrated that the invasion and migration capabilities of CRC cells were enhanced by the occurrence of EMT. HMGA2 is a chromatin remodeling factor that is able to alter chromatin architecture to activate transcriptional enhancers (49). High expression of HMGA2 is associated with cell proliferation and increased metastasis in a number of cancers (50). The results of the present study are consistent with a number of previous studies in which it was reported that HMGA2 activates EMT in cancer cells $(51,52)$. At least 11 EMT-associated molecular pathways have been reported in the literature about CRC cells, including $\beta$-catenin-associated EMT, transforming growth factor- $\beta$ and Wnt pathway-associated EMT and aberrant NOTCH-1 signaling associated EMT (53) Future studies should aim to elucidate whether there any other signaling pathways are associated with HG-induced EMT.
HG in patients with DM may alter the expression of genes that promote cell proliferation in the colon $(32-37,54)$. The rate of proliferating cell nuclear antigen-positive cells is higher in patients with CRC and DM compared with patients with CRC alone (55). HG conditions enhance cell proliferation via decreasing the population of cells arrested in the G0/G1 phase (56). In accordance with the results of the present study, HG has previously been reported to increase the proliferation of CRC cells (57).

The present study is not without limitations. The effect of $\mathrm{HG}$, which is the main feature of DM, was studied in isolation. T2DM is typically accompanied by other metabolic abnormalities, including hyperlipidemia and hyperinsulinemia $(58,59)$. These abnormalities should be considered in future studies.

In summary, the results of the present study indicate that hyperglycemia is associated with a reduction in epithelial markers and an increase mesothelial markers in CRC. The HG-induced enhanced migratory and invasive abilities of CRC cells may be attributed to EMT via the upregulation of HMGA2. The results of the present study may provide novel insights into the association between DM and CRC. 
A

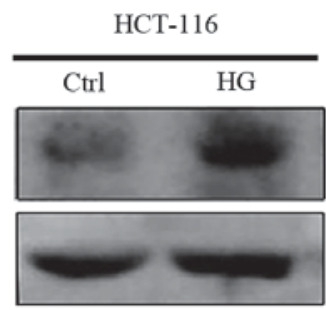

HMGA2

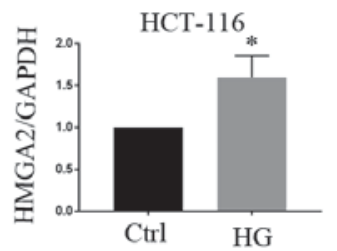

C

HCT-116

HG

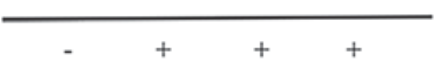

HMGA2SiRNA1

HMGA2SiRNA2

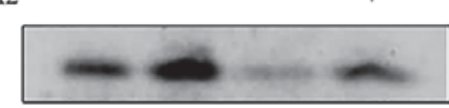

HMGA2

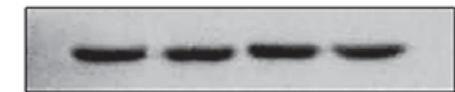

GAPDH

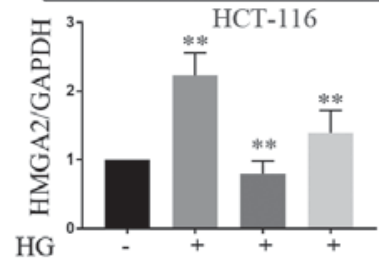

HMGA2SiRNA1

HMGA2SiRNA2
E

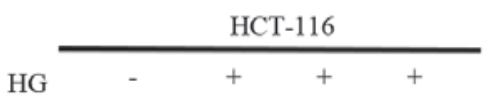

HMGA2SIRNAI

HMGA2SiRNA2
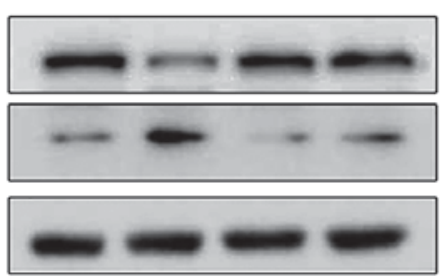

B

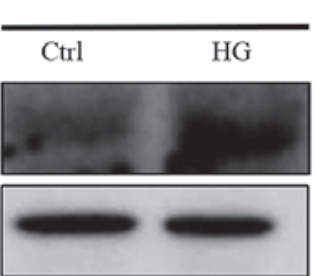

HMGA2

GAPDH

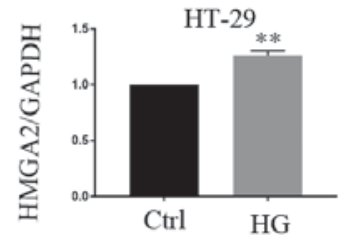

D

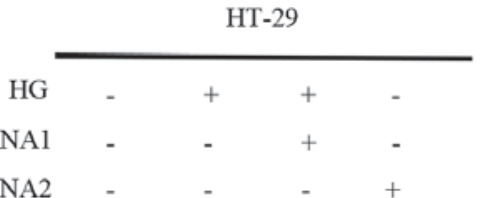

HMGA2SiRNA2

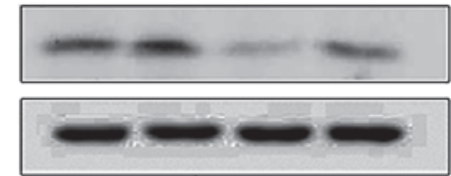

HMGA2

GAPDH

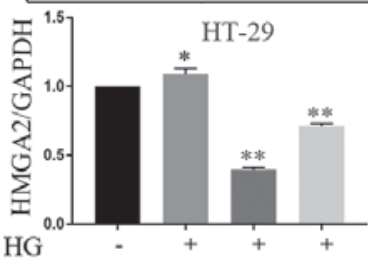

HMGA2SiRNA1

HMGA2SiRNA2
F

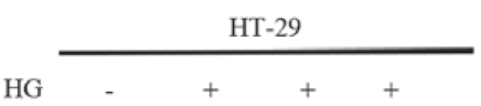

HMGA2SiRNA1

HMGA2SiRNA2

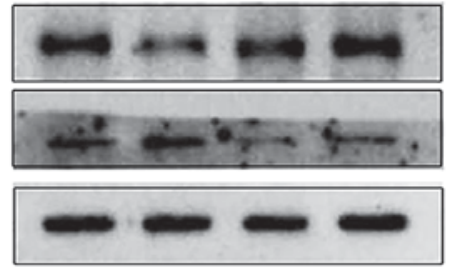

E-cadherin

Vimentin

GAPDH
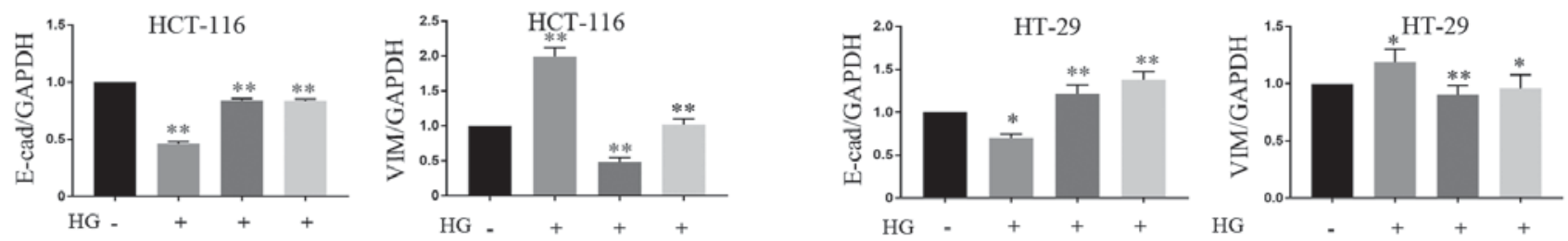

HMGA2SiRNA1 - - $\quad+\quad$ - HMGA2SiRNA1 -

HMGA2SiRNA1

HMGA2SiRNA2 -

Figure 3. HG promotes EMT by increasing the level of HMGA2 protein. Western blotting was performed to assess the expression of HMGA2 protein in (A) HCT-116 and (B) HT-29 cells. HMGA2 knockdown in (C) HCT-116 and (D) HT-29 cells was confirmed using western blotting. Western blotting analysis revealed that HMGA2 knockdown reversed EMT in (E) HCT-116 and (F) HT-29 cells. ${ }^{\mathrm{P}}<0.05$ and ${ }^{* *} \mathrm{P}<0.01$ vs. Ctrl. HG, high glucose; EMT, epithelial-mesenchymal transition; HMGA2, high-mobility group A protein 2; Ctrl, control; siRNA, small interfering RNA. 
A

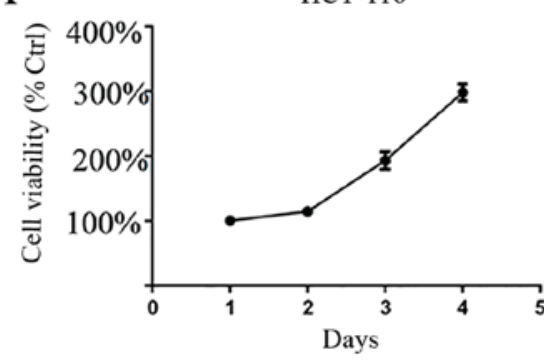

$\mathrm{C}$

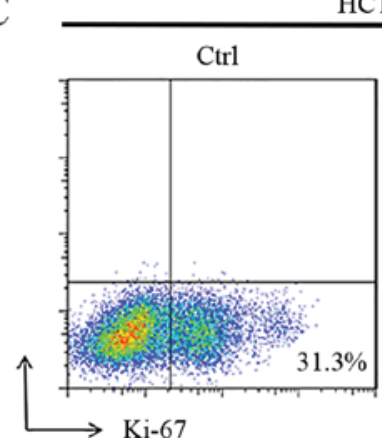

D

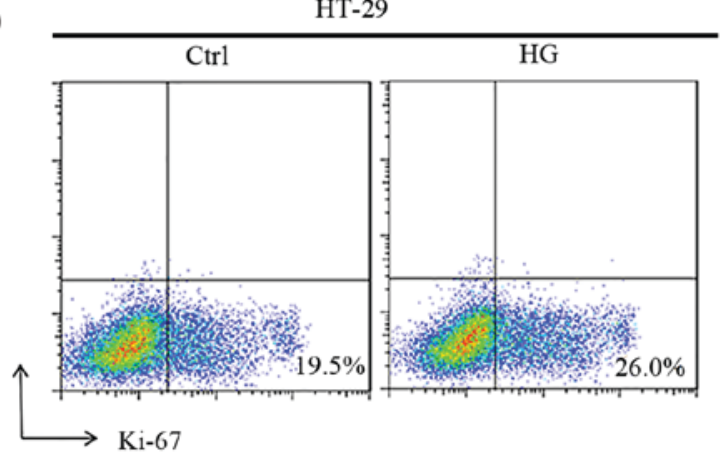

E

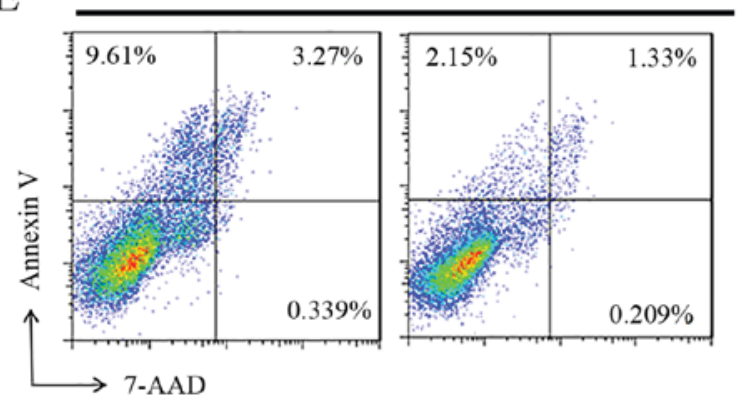

F
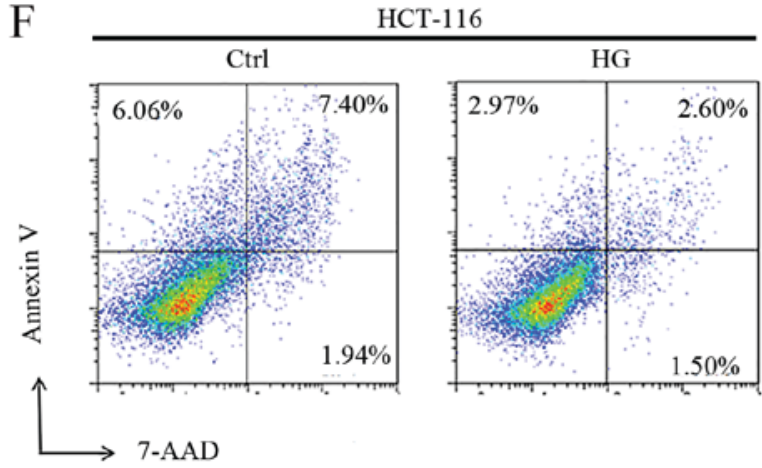

B

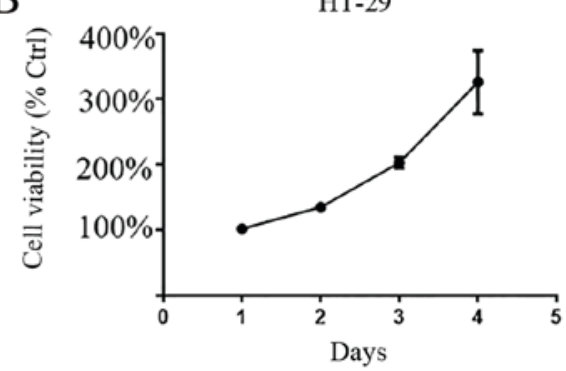

HCT-116

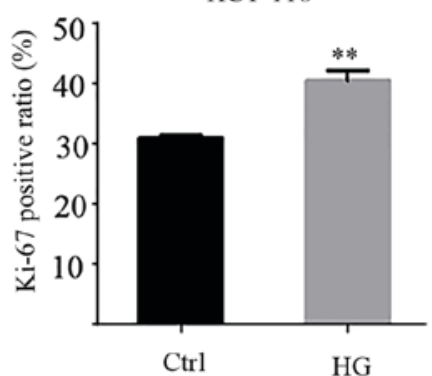

HT-29

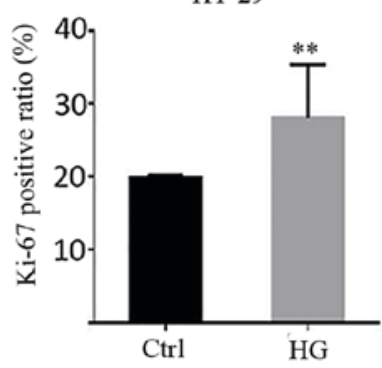

HT-29

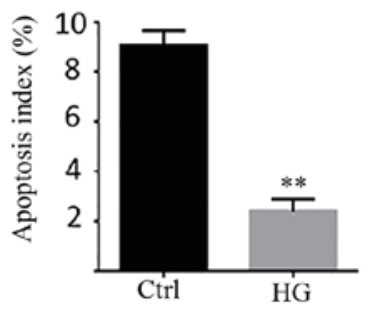

HCT-116

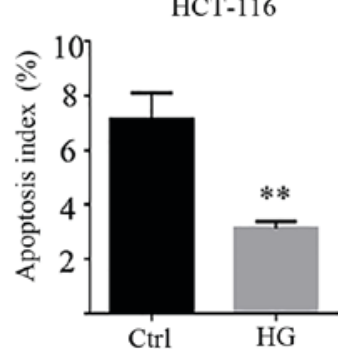

Figure 4. HG promotes cell viability and suppresses apoptosis in colorectal cancer cells. Cell viability was assessed in (A) HCT-116 and (B) HT-29 cells using an MTT assay. Cell viability was also assessed in (C) HCT-116 and (D) HT-29 using flow cytometry. An Annexin V-PE/7AAD assay was performed to measure the number of (E) HCT-116 and (F) HT-29 cells in early apoptosis (lower-right quadrant) and late apoptosis/necrosis (upper-right quadrant) cells. ${ }^{* *} \mathrm{P}<0.01$ vs. Ctrl. HG, high glucose; PE, phycoerythrin; 7AAD, 7 aminoactinomycin D; Ctrl, control. 


\section{Acknowledgements}

Not applicable.

\section{Funding}

The present study was supported by the Ningbo Science and Technology Innovation Team Program (grant nos. 2014B82002 and 2015B11050), the Public Benefit Technology and Society Development Program of Zhejiang Province (grant no. 2015C33309), the National Natural Science Foundation of China (grant nos. 81370165, 81501421 and 31301068) and the Fang Runhua Fund of Hong Kong, K. C. Wong Magna Fund in Ningbo University (grant no. NBU2013001).

\section{Availability of data and materials}

All data generated or analyzed during this study are included in this published article.

\section{Authors' contributions}

HS collected patient tumor tissue samples, JW and JC performed experimental work and conceived ideas. YX, FW, LL, YZ, XH and SB conceived ideas and evaluated the manuscript. All authors read and approved the final manuscript.

\section{Ethics approval and consent to participate}

The study protocol was reviewed and approved by the Ethics Committee of the Ningbo Urology and Nephrology Hospital and informed consent was taken from all patients.

\section{Consent for publication}

Patient provided written informed consent for the publication of all associated data and images.

\section{Competing interests}

The authors declare that they have no competing interests.

\section{References}

1. McGuire S: World cancer report 2014. Geneva, Switzerland World health organization, international agency for research on cancer, WHO Press, 2015. Adv Nutr 7: 418-419, 2016.

2. Torre LA, Bray F, Siegel RL, Ferlay J, Lortet-Tieulent J and Jemal A: Global cancer statistics, 2012. CA Cancer J Clin 65: 87-108, 2015.

3. Siegel RL, Miller KD and Jemal A: Cancer statistics, 2015. CA Cancer J Clin 65: 5-29, 2015.

4. Khan N and Mukhtar H: Cancer and metastasis: Prevention and treatment by green tea. Cancer Metastasis Rev 29: 435-445, 2010 .

5. Yoon SS and Tanabe KK: Surgical treatment and other regional treatments for colorectal cancer liver metastases. Oncologist 4: 197-208, 1999.

6. Puavilai G, Chanprasertyotin S and Sriphrapradaeng A: Diagnostic criteria for diabetes mellitus and other categories of glucose intolerance: 1997 criteria by the expert committee on the diagnosis and classification of diabetes mellitus (ADA), 1998 WHO consultation criteria, and 1985 WHO criteria. world health organizatio. Diabetes Res Clin Pract 44: 21-26, 1999.
7. Shaw JE, Sicree RA and Zimmet PZ: Global estimates of the prevalence of diabetes for 2010 and 2030. Diabetes Res Clin Pract 87: 4-14, 2010.

8. Larsson SC, Orsini N and Wolk A: Diabetes mellitus and risk of colorectal cancer: A meta-analysis. J Natl Cancer Inst 97: 1679-1687, 2005.

9. Gabriel B, Pinsard N, Gerard R and Louchet E: Association of myocardiopathy and spino-cerebellar degeneration (Friedreich's disease) Apropos of a case. Pediatrie 29: 367-377, 1974 (In French).

10. Mills KT, Bellows CF, Hoffman AE, Kelly TN and Gagliardi G: Diabetes mellitus and colorectal cancer prognosis: A metaanalysis. Dis Colon Rectum 56: 1304-1319, 2013.

11. Stein KB, Snyder CF, Barone BB, Yeh HC, Peairs KS, Derr RL, Wolff AC and Brancati FL: Colorectal cancer outcomes, recurrence, and complications in persons with and without diabetes mellitus: A systematic review and meta-analysis. Dig Dis Sci 55: 1839-1851, 2010.

12. Flood A, Mai V, Pfeiffer R, Kahle L, Remaley AT, Lanza E and Schatzkin A: Elevated serum concentrations of insulin and glucose increase risk of recurrent colorectal adenomas. Gastroenterology 133: 1423-1429, 2007.

13. Jullumstro E, Kollind M, Lydersen S and Edna TH: Diabetes mellitus and outcomes of colorectal cancer. Acta Oncol 48: 361-367, 2009.

14. Noh GY, Hwang DY, Choi YH and Lee YY: Effect of diabetes mellitus on outcomes of colorectal cancer. J Korean Soc Coloproctol 26: 424-428, 2010.

15. Kalluri R: EMT: When epithelial cells decide to become mesenchymal-Iike cells. J Clin Invest 119: 1417-1419, 2009.

16. Lamouille S, Xu J and Derynck R: Molecular mechanisms of epithelial-mesenchymal transition. Nat Rev Mol Cell Biol 15: 178-196, 2014.

17. Natalwala A, Spychal R and Tselepis C: Epithelial-mesenchymal transition mediated tumourigenesis in the gastrointestinal tract. World J Gastroenterol 14: 3792-3797, 2008.

18. Calangiu CM, Simionescu CE, Stepan AE, Cernea D, Zavoi RE and Margaritescu C: The expression of CK19, vimentin and E-cadherin in differentiated thyroid carcinomas. Rom J Morphol Embryol 55: 919-925, 2014.

19. Loboda A, Nebozhyn MV, Watters JW, Buser CA, Shaw PM, Huang PS, Van't Veer L, Tollenaar RA, Jackson DB, Agrawal D, et al: EMT is the dominant program in human colon cancer. BMC Med Genomics 4: 9, 2011.

20. Flores-Lopez LA, Martinez-Hernandez MG, ViedmaRodriguez R, Diaz-Flores M and Baiza-Gutman LA: High glucose and insulin enhance uPA expression, ROS formation and invasiveness in breast cancer-derived cells. Cell Oncol (Dordr) 39: 365-378, 2016.

21. He L, Lou W, Ji L, Liang W, Zhou M, Xu G, Zhao L, Huang C, Li R, Wang $\mathrm{H}$, et al: Serum response factor accelerates the high glucose-induced Epithelial-to-Mesenchymal Transition (EMT) via snail signaling in human peritoneal mesothelial cells. PLoS One 9: e108593, 2014.

22. Gou W, Zhou X, Liu Z, Wang L, Shen J, Xu X, Li Z, Zhai X, Zuo D and Wu Y: CD74-ROS1 G2032R mutation transcriptionally up-regulates Twist 1 in non-small cell lung cancer cells leading to increased migration, invasion, and resistance to crizotinib. Cancer Lett 422: 19-28, 2018.

23. Tam L and Weinberg A: The Epigenetics of epithelial-mesenchymal plasticity in cancer. Nat Med 19: 1438-1449, 2013.

24. Thuault S, Tan EJ, Peinado H, Cano A, Heldin CH and Moustakas A: HMGA2 and Smads co-regulate SNAIL1 expression during induction of epithelial-to-mesenchymal transition. J Biol Chem 283: 33437-33446, 2008.

25. Tan EJ, Thuault S, Caja L, Carletti T, Heldin CH and Moustakas A: Regulation of transcription factor Twist expression by the DNA architectural protein high mobility group A2 during epithelial-to-mesenchymal transition. J Biol Chem 287: 7134-7145, 2012.

26. Dong J, Wang R, Ren G, Li X, Wang J, Sun Y, Liang J, Nie Y, Wu K, Feng B, et al: HMGA2-FOXL2 axis regulates metastases and epithelial-to-mesenchymal transition of chemoresistant gastric cancer. Clin Cancer Res 23: 3461-3473, 2017.

27. Li W, Wang Z, Zha L, Kong D, Liao G and Li H: HMGA2 regulates epithelial-mesenchymal transition and the acquisition of tumor stem cell properties through TWIST1 in gastric cancer. Oncol Rep 37: 185-192, 2017.

28. Grossarth-Maticek R and Eysenck HJ: Length of survival and lymphocyte percentage in women with mammary cancer as a function of psychotherapy. Psychol Rep 65: 315-321, 1998. 
29. Shi Z, Wu D, Tang R, Li X, Chen R, Xue S, Zhang C and Sun X: Silencing of HMGA2 promotes apoptosis and inhibits migration and invasion of prostate cancer cells. J Biosci 41: 229-236, 2016.

30. Alco G, Bozdogan A, Selamoglu D, Pilanci KN, Tuzlali S, Ordu C, Igdem S, Okkan S, Dincer M, Demir G and Ozmen V: Clinical and histopathological factors associated with Ki-67 expression in breast cancer patients. Oncol Lett 9: 1046-1054, 2015.

31. Hanahan D and Weinberg RA: Hallmarks of cancer: The next generation. Cell 144: 646-674, 2011.

32. Ryu TY, Park J and Scherer PE: Hyperglycemia as a risk factor for cancer progression. Diabetes Metab J 38: 330-336, 2014.

33. Abhijit S, Bhaskaran R, Narayanasamy A, Chakroborty A, Manickam N, Dixit M, Mohan V and Balasubramanyam M: Hyperinsulinemia-induced vascular smooth muscle cell (VSMC) migration and proliferation is mediated by converging mechanisms of mitochondrial dysfunction and oxidative stress. Mol Cell Biochem 373: 95-105, 2013.

34. Beckner ME, Stracke ML, Liotta LA and Schiffmann E: Glycolysis as primary energy source in tumor cell chemotaxis. J Natl Cancer Inst 82: 1836-1840, 1990.

35. Rose DP and Vona-Davis L: The cellular and molecular mechanisms by which insulin influences breast cancer risk and progression. Endocr Relat Cancer 19: R225-R241, 2012.

36. Joshi S, Liu M and Turner N: Diabetes and its link with cancer: Providing the fuel and spark to launch an aggressive growth regime. Biomed Res Int 2015: 390863, 2015.

37. Masur K, Vetter C, Hinz A, Tomas N, Henrich H, Niggemann B and Zanker KS: Diabetogenic glucose and insulin concentrations modulate transcriptome and protein levels involved in tumour cell migration, adhesion and proliferation. Br J Cancer 104: 345-352, 2011

38. Kang X, Kong F, Wu X, Ren Y, Wu S, Wu K, Jiang Z and Zhang W: High glucose promotes tumor invasion and increases metastasis-associated protein expression in human lung epithelial cells by upregulating heme oxygenase-1 via reactive oxygen species or the TGF- $\beta 1 /$ PI3K/Akt signaling pathway. Cell Physiol Biochem 35: 1008-1022, 2015.

39. Lontchi-Yimagou E, Sobngwi E, Matsha TE and Kengne AP: Diabetes mellitus and inflammation. Curr Diab Rep 13: 435-444, 2013.

40. Hu B, Meigs B, Li Y, Rifai N and Manson E: Inflammatory markers and risk of developing type 2 diabetes in women. Diabetes 53: 693-700, 2004.

41. Han TS, Sattar N, Williams K, Gonzalez-Villalpando C, Lean ME and Haffner SM: prospective study of C-reactive protein in relation to the development of diabetes and metabolic syndrome in the Mexico City Diabetes study. Diabetes Care 25: 2016-2021, 2002.

42. Hotamisligil GS, Shargill NS and Spiegelman BM: Adipose expression of tumor necrosis factor-alpha: Direct role in obesitylinked insulin resistance. Science 259: 87-91, 1993.

43. Rokavec M, Oner MG, Li H, Jackstadt R, Jiang L, Lodygin D, Kaller M, Horst D, Ziegler PK, Schwitalla S, et al: IL-6R/STAT3/ miR-34a feedback loop promotes EMT-mediated colorecta cancer invasion and metastasis. J Clin Invest 124: 1853-1867, 2014.

44. Cheng XS, Li YF, Tan J, Sun B, Xiao YC, Fang XB, Zhang XF, Li Q, Dong JH, Li M, et al: CCL20 and CXCL8 synergize to promote progression and poor survival outcome in patients with colorectal cancer by collaborative induction of the epithelialmesenchymal transition. Cancer Lett 348: 77-87, 2014.
45. Li W,Zhang L, Chen X, Jiang Z,Zong L and Ma Q: Hyperglycemia promotes the epithelial-mesenchymal transition of pancreatic cancer via hydrogen peroxide. Oxid Med Cell Longev 2016: 5190314, 2016

46. Pena C, Garcia JM, Silva J, Garcia V, Rodriguez R, Alonso I, Millan I, Salas C, de Herreros AG, Munoz A and Bonilla F: E-cadherin and vitamin D receptor regulation by SNAIL and ZEB1 in colon cancer: Clinicopathological correlations. Hum Mol Genet 14: 3361-3370, 2005.

47. He X, Chen Z, Jia M and Zhao X: Downregulated E-cadherin expression indicates worse prognosis in Asian patients with colorectal cancer: Evidence from meta-analysis. PLoS One 8: e70858, 2013.

48. Toiyama Y, Yasuda H, Saigusa S, Tanaka K, Inoue Y, Goel A and Kusunoki M: Increased expression of Slug and Vimentin as novel predictive biomarkers for lymph node metastasis and poor prognosis in colorectal cancer. Carcinogenesis 34: 2548-2557, 2013.

49. Boo LM, Lin HH, Chung V, Zhou B, Louie SG, O'Reilly MA, Yen Y and Ann DK: High mobility group A2 potentiates genotoxic stress in part through the modulation of basal and DNA damage-dependent phosphatidylinositol 3-kinase-related protein kinase activation. Cancer Res 65: 6622-6630, 2005.

50. Fusco A and Fedele M: Roles of HMGA proteins in cancer. Nat Rev Cancer 7: 899-910, 2007.

51. Wang Y, Le Y, Xue JY, Zheng ZJ and Xue YM: Let-7d miRNA prevents TGF-betal-induced EMT and renal fibrogenesis through regulation of HMGA2 expression. Biochem Biophys Res Commun 479: 676-682, 2016.

52. Zhao XP, Zhang H, Jiao JY, Tang DX, Wu YL and Pan CB: Overexpression of HMGA2 promotes tongue cancer metastasis through EMT pathway. J Transl Med 14: 26, 2016.

53. Matejka M, Finek J and Kralickova M: Epithelial-mesenchymal transition in tumor tissue and its metastatic spread of cancer. Klin Onkol Winter 30: 20-27, 2017 (In Czech).

54. Tomas NM, Masur K, Piecha JC, Niggemann B and Zanker KS: Akt and phospholipase Cgamma are involved in the regulation of growth and migration of MDA-MB-468 breast cancer and SW480 colon cancer cells when cultured with diabetogenic levels of glucose and insulin. BMC Res Notes 5: 214, 2012

55. Yang B, Huang CZ, Yu T, Zhou SN, Liu Q, Liu GJ, Chen S and Han FH: Metformin depresses overactivated Notch1/Hes1 signaling in colorectal cancer patients with type 2 diabetes mellitus. Anticancer Drugs 28: 531-539, 2017.

56. Yang IP, Tsai HL, Huang CW, Lu CY, Miao ZF, Chang SF, Juo SH and Wang JY: High blood sugar levels significantly impact the prognosis of colorectal cancer patients through down-regulation of microRNA-16 by targeting Myb and VEGFR2. Oncotarget 7: $18837-18850,2016$

57. Lee SK, Moon JW, Lee YW, Lee JO, Kim SJ, Kim N, Kim J, Kim HS and Park SH: The effect of high glucose levels on the hypermethylation of protein phosphatase 1 regulatory subunit $3 \mathrm{C}$ (PPP1R3C) gene in colorectal cancer. J Genet 94: 75-85, 2015.

58. Haffner M: Diabetes, hyperlipidemia, and coronary artery disease. Am J Cardiol 83: 17F-21F, 1999.

59. O'Dea K, Lion RJ, Lee A, Traianedes K, Hopper JL and Rae C: Diabetes, hyperinsulinemia, hyperlipidemia in small aboriginal community in northern Australia. Diabetes Care 13: 830-835, 1990. International (CC BY-NC-ND 4.0) License. 